\title{
Impact of Urinary Incontinence on Self Esteem and Quality of Life of Elderly Females Residing in Assisted Living Facilities
}

\author{
Rasha Ahmed Fouad, Assistant Professor \\ Gerontological Nursing, Faculty of Nursing, Alexandria University \\ Sarah Ali Hafez, Lecturer \\ Gerontological Nursing, Faculty of Nursing, Alexandria University
}

\begin{abstract}
Urinary incontinence (UI) is one of the major problems that has a negative impact on the women's psychological wellbeing and self esteem. It is also one of the threatening factors which can cause withdrawal from social activities and decreased quality of life. Objective: The aim of this study is to determine the Impact of urinary incontinence on self esteem and quality of life of elderly females residing in assisted living facilities. Setting: The study was carried out in two of the governmental assisted living facilities (elderly homes) in Alexandria. Subjects: The study included, one hundred elderly females aged 60 years and above, able to communicate effectively, and accept to participate in the study. Tools: Three tools were used; the Socio-demographic and Clinical Data Structured Interview Schedule, the Rosenberg SelfEsteem Scale (RSES), and the Kings Health Questionnaire (KHQ). Results: The majority of the study females had UI for three years and more. UI affected positively the self esteem and quality of life. Females with lower quality of life were young old, single, house wife, and with inadequate enough income. Conclusion: Urinary incontinence had a great impact on all domains of quality of life of the study females. Shame, embarrassment and / or their belief that UI is a normal part of aging are among the reasons for not seeking help. Recommendations: Educational programs for older adults and their care givers should focus on developing awareness about UI, the importance of seeking advice in order to develop effective coping strategies, increase self esteem, and improve QoL.
\end{abstract}

Keywords: Urinary incontinence; Quality of life; Self esteem; Elderly females; nurses' role.

\section{Introduction}

Urinary incontinence (UI) is defined as the involuntary loss of urine so severe as to have social and/or hygienic consequences for older adults and/or their caregivers. It is a common clinical condition and one of the most distressing and debilitating conditions worldwide. It affects women of all ages across different cultures and races. It often increases as women age ${ }^{(1)}$. UI is not a disease, but rather a symptom resulting from impairment of the bladder or the sphincter mechanism. The most common types of UI are stress, urge, and mixed UI may not be life threatening but is threatening quality-of-life ${ }^{(2)}$.

Voluntary control of the bladder is a prerequisite for the sense of normality, self- esteem, life satisfaction, and independence, which begins in childhood as something personal not socially talked about. Therefore, urine loss is a condition with a profound impact on social life for children, adults, and older adults ${ }^{(3)}$.

In the United State (2010), UI affects up to $30 \%$ of community-dwelling older adults and more than $50 \%$ of nursing home residents. It is about 2-3 times more common in women than in men until 80 years of age, after which UI rates are similar $^{(4)}$. In Australia (2006), it is estimated that there are 3.84 million people with UI approximately $38.1 \%$ women and $10.2 \%$ men. ${ }^{(5)}$. In a British survey (2006), incontinence was estimated to be over twice as prevalent in women $(14 \%)$ as in men $(6.6 \%)^{(6)}$. While in Egypt, the prevalence of 
UI was $54.8 \%$ which is higher when compared to other reports ${ }^{(7)}$. Despite of this high prevalence, yet up to one-half of the cases are under reported because individuals with UI usually do not seek medical intervention ${ }^{(2)}$. A study of 2100 older women from California, found the prevalence of treatment seeking for incontinence issues was low across all ethnic groups, even when the women had clinically severe symptoms and access to a health provider $^{(8)}$. The authors hypothesis that this may be because many women regard UI as more of a personal self-care or hygiene problem than a true medical condition, and hence manage it privately. Embarrassment and the perception that UI is an expected consequence of aging are common factors in lack of treatment ${ }^{(9)}$.

Literature review identified age as a consistently reported risk factor for UI; however, UI is not considered a normal consequence of aging. UI has a major impact on physical, emotional and social health and wellbeing, including sleep problems, low self esteem, depression, and psychological distress. In addition to restrictions in physical activity, relationships, feelings of helplessness, increased risk of urinary tract infections (UTIs), pressure ulcers, falls, and fractures, all of which may lead to functional impairment and decline in overall health status ${ }^{(10)}$. The restricted activities not only interfere with interpersonal relationships, but also it can damage self-esteem as a result of the shame and embarrassment some older adults feel, and those afflicted women health and quality of life $(\mathrm{QoL})^{(11)}$. DuBeau et al. study (2006) demonstrated that UI was significantly associated with worse QoL in older adults with functional impairments ${ }^{(12)}$.

UI is still a taboo in Western societies, associated with myths and social restrictions. In fact, women often choose not to leave their home for fear and shame of losing urine in public, feeling wet and smelling, not finding a bathroom when they need to change clothes or their protective pad. As a result, several women with UI avoid going to parties, long trips, attending religious activities and participating in physical activities such as walking ${ }^{(13)}$.

UI can range from mild (for example, a few drops when coughing or sneezing) to severe (such as flooding without warning). However, the bother and impact of urinary incontinence is not simply related to severity. It depends on many older adults' characteristics such as age, gender, activity level, context, lifestyle and relationships ${ }^{(8)}$. Very mild urinary incontinence can have a major and devastating impact on one person, while another with more severe incontinence may manage it with less stress. Although both stress incontinence and overactive bladder are treatable with physiotherapy, medication or surgery, there remains a profound stigma and feeling of humiliation attached to these conditions ${ }^{(14)}$.

UI can have significant negative impact on self esteem; it affects social aspects of QoL and $\mathrm{ADL}^{(15)}$. The psychological impact of this condition must neither be underestimated nor ignored. The effect that UI has on daily life can differ greatly, depending on the etiology and severity of the condition and, equally, individual personality and coping strategies $^{(3)}$. This reiterates the importance of maintaining a holistic approach to treatment, thus allowing effective identification and treatment of individual requirements, both physical and psychological $^{(16)}$.

Gerontological nurses have an important role to play in assisting older adults to cope and live with their condition and better manage it in their daily lives, regardless of where they are in the treatment trajectory. They play an important role in assisting older adults to deal with the emotional impact of UI; this can be achieved through discussing older adults' feelings and worries ${ }^{(17)}$. Also nurses can offer knowledge and support that can assist clients to problem-solving and develop plans for living more effectively with urinary incontinence. This will improve 
clients' QoL, increase self esteem, prevent secondary problems and give them more control over their lives ${ }^{(18)}$.

Research on UI and QoL is scattered, inconsistent, and varies widely in methodological rigor and substantive focus. Nevertheless, despite the large amount of researches, a review of the literature on QoL studies in women with UI is still lacking. So the study was done to explore the relationship between UI, self esteem and QOL \& of elderly females in Egypt.

\section{Aim of the Study}

The aim of this research is to determine the impact of urinary incontinence on self esteem and quality of life of female elders residing in assisted living facilities.

\section{Research Question:}

What is the impact of urinary incontinence on self esteem and quality of life of elderly females residing in assisted living facilities?

\section{Materials and Method}

\section{Materials}

Design: The study followed a descriptive design.

Setting: The study was carried out in two of the governmental assisted living facilities (elderly homes) in Alexandria, namely Dar El-Hana, and Dar El-Hadaya, These were selected randomly by ballot.

Subjects: The subjects comprised 100 female elders residing in the previously mentioned settings, and fulfilling the following criteria, aged 60 years and above, have UI, able to communicate effectively, and accept to participate in the study.
Tools:

Tool I: Older Adults' Socio-demographic and Clinical Data Structured Interview Schedule

It was developed by the researchers based on relevant literature to collect information from the study subjects about their socio-demographic characteristics, medical problems, and medications used. History of UI (onset, duration, frequency, and seeking help). Social activities: social relationships either inside or outside the elderly home, participation in recreational activities, and leisure time activities.

Tool II: The Rosenberg Self-Esteem Scale (RSES)

This scale was developed by Rosenberg in $1965^{(19)}$ to measure the global selfesteem. The Rosenberg self-esteem scale is a ten-item Likert scale with items answered on a four-point scale ranging from strongly agree to strongly disagree. The scale contains five positively worded items and five negatively worded items. RSES was translated into Arabic and approved to be valid and reliable $(\mathrm{r}=0.88)$ by Ebrahim et al. $(2007)^{(20)}$. The Arabic version of this scale was used in this study. The score of the scale was calculated as follows:

- For items 1,2,4,6, and 7: Strongly Agree $=3$, Agree $=2$, Disagree $=1$, and strongly Disagree $=0$.

- For items 3,5,8,9, and10 (which are reversed in valence): Strongly Agree $=0$, Agree $=1$, Disagree $=2$, and Strongly Disagree $=3$.

The total score ranges from 0-30. Scores more than 25 suggest high self-esteem, between 15 and 25 are within normal range of self-esteem, and scores below 15 suggest low self-esteem.

Tool III: The Kings Health Questionnaire (KHQ)

KHQ is a standardized questionnaire developed by Linda \& Con $(1997)^{(21)}$ to assess the impact of urinary incontinence on health related QoL, it consists of 21 
questions, divided into seven domains: general health perception, UI impact, role limitation, physical/social limitations, personal relationships, emotions and sleep/energy. Each domain ranging from 0 to 100 ; in that, the higher the score, the worst the QOL. Two other independent scales were applied to evaluate severity of $\mathrm{UI}$, as well as presence and intensity of urinary symptoms. KHQ was translated into Arabic and approved to be valid and reliable $(r=0.95)$ by Mohammed $S$ et al $(2015)^{(22)}$. The Arabic version of this questionnaire was used in this study.

\section{Scoring system as follow:}

\section{- PART 1:}

1. General Health Perceptions:

Very good 1 Good 2 Fair 3 Poor 4 Very poor 5 Score $=($ Score to $\mathrm{Q} 1-1) / 4) \mathrm{X}$ 1002 ).

\section{Incontinence Impact:}

Not at all 1, A little 2, Moderately 3, A lot 4 Score $=(($ Score to $\mathrm{Q} 2-1) / 3) \mathrm{x}$ 100.

Not at all 1, A little 2, Moderately 3, A lot 4 Score $=(($ Score to $\mathrm{Q} 2-1) / 3) \mathrm{x}$ 100 .

\section{- PART 2:}

Individual scores as recorded at the top of each column of possible responses:

3. Role limitations Score $=($ Scores to $\mathrm{Q}$ $3 \mathrm{~A}+3 \mathrm{~B})-2) / 6) \times 1004)$.

4. Physical limitations Score $=($ Scores to $\mathrm{Q} 4 \mathrm{~A}+4 \mathrm{~B})-2) / 6) \times 1005$ ).

5. Social limitations [If $5 \mathrm{C}>/=1$ ] Score $=($ Score to $\mathrm{Q} 4 \mathrm{C}+4 \mathrm{D}+5 \mathrm{C})-3) / 9) \mathrm{X}$ 100 [If $5 \mathrm{C}=0$ ] $\quad$ Score $=($ Score to $\mathrm{Q}$ $4 \mathrm{C}+4 \mathrm{D})-2) / 6) \times 100$.

6. Personal relationships [If $5 \mathrm{~A}+5 \mathrm{~B}$ $>=2]$ Score $=($ Scores to $\mathrm{Q} 5 \mathrm{~A}+5 \mathrm{~B})-$ 2) $/ 6) \times 100$ [If $5 A+5 B=1$ ] Score $=$ $($ Scores to $Q 5 A+5 B)-1) / 3$ ) $\times 100$ [If $5 \mathrm{~A}+5 \mathrm{~B}=0$ ] Treat as missing value 7 ).

7. Emotions Score $=($ Score to $\mathrm{Q} 6 \mathrm{~A}+$ $6 \mathrm{~B}+6 \mathrm{C})-3) / 9) \times(008)$.
8. Sleep/energy Score $=($ Scores to $\mathrm{Q}$ $7 \mathrm{~A}+7 \mathrm{~B})-2) / 6) \times(009)$.

9. Severity measures Score $=($ Scores to $\mathrm{Q} 8 \mathrm{~A}+8 \mathrm{~B}+8 \mathrm{C}+8 \mathrm{D})-4) / 12) \times 100$.

\section{- PART 3:}

Symptom severity scale score Omitted 0, A little1 Moderately 2, A lot 3.

- Total QoL $=$ sum of questions 3 to $8 /$ $68 * 100$.

\section{Method}

- An official letter was issued from the Faculty of Nursing, Alexandria University to the branch of the Ministry of social solidarity in Alexandria to obtain permission to visit the selected homes for data collection.

- An official letter was issued with the approval of the Ministry of Social Solidarity to the director of each of the selected homes. The directors were contacted personally to obtain their approval to collect the data. As well, they were informed about the purpose of the research and the time of data collection.

- Tool I the socio-demographic and clinical data structured interview schedule was developed by the researchers after reviewing of relevant literature.

- The Arabic version of tool II and Tool III were used in the study.

- A pilot study was carried out before embarking in the actual study in order to ascertain the clarity and applicability of all the study tools, to estimate the time required for interviewing the elders, and to identify obstacles that may be faced during data collection. The pilot study was conducted on 10 elders (from Dar Mohamed Ragab) after securing their informed consent, privacy, and confidentiality. Results of this pilot study revealed that all tools were clear, applicable, and consuming about 30 45 minutes for their application. 
- The selection of the two governmental homes was done randomly by ballot. The name of each of the six available homes in Alexandria was written on pieces of paper then folded and put them all in a ball, mixing them and pulling two of them. The result revealed that Dar El-Hana and Dar El-Hadaya were the settings for the study.

- The researchers used to go to the study settings based on a schedule. The researcher started data collection based on the schedule days from 9 am to 1 pm; all female elders who fulfill the study criteria were included in the study.

- Each subject was interviewed individually by the researchers in her room during the morning shift. The researchers started the interview by introducing themselves, explaining the purpose of the study and ensuring that the elder is physically and psychologically comfort and accept to participate in the study.

- The Data collection started from first of October to end of December 2016.

\section{Ethical considerations:}

An informed consent from the study subjects to participate in the study was being obtained after explanation of the study purpose. Confidentiality of the collected data, privacy and anonymity of the study subjects and the right to withdraw at any time was assured.

\section{Statistical Analysis}

Data were fed to the computer and analyzed using IBM SPSS software package version 20.0. Qualitative data were described using number and percent. Quantitative data were described using range (minimum and maximum), mean, and standard deviation. Significance of the obtained results was judged at the $5 \%$ level.

The tests used were:
- Chi-square test: For categorical variables, to compare between different groups

- Fisher's Exact or Monte Carlo correction: Correction for chi-square when more than $20 \%$ of the cells have expected count less than 5 .

\section{Results}

Socio-demographic characteristics of study female elders: more one half of the study females were aged 75 years and above, with low level of education, $40 \%$ were either widow or divorced, and $80 \%$ were house wife.

Table (1) illustrates the distribution of the studied elderly females according to their history of UI. It was observed that, $84 \%$ of the studied women had UI from three years and more, day and night micturation episodes was reported by $62 \%$ of the studied females and three fifth $(61 \%)$ wake up more than two times at night. The table also shows that $47 \%$ of the studied women reported leakage large amount of urine that wet their internal and external clothes. More than half $(55.0 \%)$ of the studied females did not seek any help for their problem. Among the reasons for not seeking help are embarrassment which was prevailing among $70.9 \%$ of the studied women, followed by being able to deal with the condition $45.4 \%$ and thinking that UI is a normal part of aging $41.8 \%$.

Figure (1) represents the distribution of the studied elderly females according to their Self-Esteem, It was noted that $52.0 \%$ of the studied elders had high self-esteem, $38.0 \%$ had normal range of self esteem, while the rest $(10.0 \%)$ had low self-esteem.

Table (2) shows the relation between self-esteem of the studied elderly females and their socio-demographic characteristics. The results indicated that, $52.0 \%$ of the studied females had high self esteem. Of them 24 were 60 to less than 75 years and 28 were 75 years \& more. Regarding marital status, widows or divorced had low self esteem $40 \%$ for each. Statistically 
significant relationship detected between marital status and self-esteem $(p=0.030)$. No statistically significant difference was observed between level of education, occupation, income and self esteem $(\mathrm{p}=0.348,0.541$, and 0.567 respectively).

Figure (2) presents the distribution of the studied elderly females according to mean score of their QoL domains. The mean score of severity measures, incontinence impact, general health perception, and emotion domains were higher than the other QoL domains (73.2, 73.0, 61.7, and 61.3 respectively).

Table (3) clarifies the relation between socio-demographic characteristics and total mean score of the QoL of studied elderly females. It was found that, total mean scores of QoL were higher among young old females (60 to less than 75 years), single, illiterate, house wife, and those who reported they do not have enough money. Statistically significant relations were found between total mean score of QoL and the elderly females' age (0.009), marital status $(\mathrm{p}=0.014)$, occupation before retirement $(\mathrm{p}=0.021)$, and income $(\mathrm{p}=0.018)$.

Table (4) shows the relation between socio-demographic characteristics and QoL domains of the studied elderly females. All QoL domains were higher in the age group 60 to less than 75 years (young old), single, house wife, and those who had inadequate income, these findings means that, this groups of the studied females had worse QoL, Statistically significant relations were found between age and all QoL domains $(p \leq 0.05)$. On the other hand, A statistically significant relation was found only between general health perception domain and the educational level of studied elderly females $(\mathrm{p}=0.047)$.

Table (5) denotes the relation between mean score of QoL domains of the studied female elders and their self-esteem. The table shows statistically significant relations between all QoL domains and self esteem.

Table (6) illustrates the relation between mean total score of the QoL and self-esteem of the studied elderly females and the duration of urinary incontinence. The table revealed positive relations between duration of urinary incontinence and mean score of QoL, and self esteem of the studied elders. The longer the duration of UI the worse the QoL and the lower the self esteem of the studied elders. A statistically significant relation was found between the duration of UI and the QoL $(p=0.023)$, while no statistical difference was observed with self esteem $(\mathrm{p}=0.50)$.

\section{Discussion}

Urinary incontinence in women is a global health problem and its prevalence increases with advancing age. UI is distressing and has a negative effect on health related QoL. Results of the present study revealed that, the majority of the studied elderly females reported having UI for three years and more. For more than one half UI occur day and night. With regard to the amount of urine leak out, the current study divulged that less than one half of the study older adults wet their undergarments, and the minority wet their clothes in addition to the bed (table 1). These findings are in agreement with that of Abd el geleel $(2012)^{(23)}$ who revealed that, the majority of her studied females reported having UI for more than 3 years, more than one half of her study subjects reported three times and more of micturition during night, and around one half of them reported to wet their internal clothes only.

As regards seeking help the present study revealed that more than one half of the study subjects reported that they did not seek any help because of embarrassment. Around one half of them believe that they can deal with the problem independently and unfortunately, less than one half of them consider UI as part of ageing (table1). This is in accordance with a study carried out by Horrocks et al. (2004) $)^{(24)}$ who reported that UI among their study subjects was commonly viewed as an inevitable aspect of ageing and, as such, something to be accepted and managed independently. 
Shame and embarrassment combined with generational differences in attitudes to disclosure about personal matters also prevented people from seeking advice. The finding of the present study is also in consistent with that Abd El Geleel (2012) $)^{(23)}$ who divulged that the majority of her study females do not seek any help. As well embarrassment was the main reason reported by approximately two third of the study women. However, this finding contradicts what Newman ${ }^{(25)}$ reported in his study, where $65 \%$ of respondents sought professional advice concerning urinary incontinence. This may be related to the cultural difference and also most of his study subjects reported to have higher level of education.

Results of the present the study reveal that UI is more observed in females 75 years and older; widow and those with low educational level (table 2). These findings supports those of El-Azab et al. (2007) ${ }^{(7)}$, Abd El Geleel $(2012)^{(23)}$, and Kirss et al. $(2013)^{(26)}$.

The present study showed high level of self-esteem among one half of the study females (Figure 1). This may be related to their believe that UI is part of the aging process, and they are able to cope with its consequences. This finding supports those of Horrocks et al. $(2004)^{(24)}$ who revealed that self-management of urinary incontinence helps to maintain self esteem when other disabling conditions dominate older people's lives. Another study also reported that older adults may have other co-morbidities affecting their QoL and self esteem which helped their adaptation psychologically and behaviorally to $\mathrm{UI}^{(27)}$. Also Thomas and colleagues reported in their study that coping ability may increase with aging ${ }^{(28)}$. A study in Korea by Chui et al. (2011) reported the mean self-esteem to be 28.23. Another study carried out by Chedraui et al. (2010) in Ecuador, revealed the mean self-esteem in the aged women to be $26.6^{(29)}$. These figures are lower than the one reported in the present study 58.00 \pm 18.71 (table 5). This difference can

ASNJ Vol.19 No. 1, 2017 be due to cultural differences between countries.

Concerning the relation between self esteem of the studied women and their socio-demographic characteristics, more than one half of the studied subjects aged 75 years and more have either high self esteem or normal range of self esteem, the differences are not statistically significant. These results contradicts those of Bergland et al. (2010) who revealed a significant relationship between increasing age and lower self-esteem scores ${ }^{(30)}$.

Subjects with basic education were found to have high self esteem, with no significant difference (table 2). This contradicts the results of Kim et al. (2014) who reported that the education level has a statistical significance relation with self esteem, the high the education the higher the self esteem score ${ }^{(31) .}$

Marital status affected significantly the self esteem level. Widowed and/or divorced females reported low self esteem (table 2). Females who claimed to have enough income showed higher self esteem. This is in agreement with a study carried out by Young et al. (2008) who reported that elders who consider their pocket money enough had a higher self esteem when compared with their counterparts ${ }^{(32)}$. In addition, a study done by Franak et al. (2012) showed that single, low-income, and less educated elderly had low levels of self-esteem ${ }^{(33)}$.

UI is not a problem that threaten elderly females their lives or limits their activities, but disturbs their lifestyles and especially their functioning and psychological well-being. With reference to the studied subjects QoL domains, the mean score of severity measures and incontinence impact, general health perception, emotions domains were higher than the other QoL domains, which mean poor QoL of the studied females. This is in agreement with many other studies where Bertera (2002) reported that UI have negative psychological effects, including depression, which may further impact the QoL of older adults $^{(34)}$. Hajjar (2004) reported that older 
people with UI experience interference with their social activities, such activities include travel, shopping, recreational activities and entertainment events outside the home that affect QoL domains ${ }^{(35)}$. Women with UI usually limit their physical and social activities because they fear of urinary leakage ${ }^{(36)}$. A research in Turkey by Kocak et al. (2005) found that UI had a negative impact on the QoL of $87.2 \%$ of these patients with mild to moderate severity ${ }^{(37)}$. Moreover, Teunisse et al. (2006) ${ }^{(38)}$ and Mladenovic $(2011)^{(39)}$ investigated the impact of UI on the QoL of the elderly; they found that half of the patients had anxiety, distress and disappointment which were manifested mostly in their activities in public places and affect their QoL. The results of all previous studies and the present study are in accordance with the literature since women with UI report greater impairment in their QoL.

As regards the relation between total mean score of QoL of the studied subjects and their sociodemographic characteristics. Poorer QoL was observed among young old females (table 3). Statistically significant relations were found between age and all QoL domains. This may be because with increasing age the older adult is usually less physically and socially active, thus UI can affect more his physical activity.

As for the marital status of the study elders, single females have higher mean score of QoL. Concerning the level of education of the studied subjects, those with university education had better QoL than the other groups. This finding may be due to the fact that education is an important factor in enhancing the health and wellbeing of individuals. A higher educational level has a positive impact on all aspects of person's life. These results support previous studies done by Kalda et al. $(2008)^{(40)}$, El husseini $(2013)^{(41)}$ and Ibrahim $(2014)^{(42)}$. Also the present study revealed that, poorer score of QoL was among housewives and those who reported to have inadequate income. This may be interpreted by the fact that a higher income leads to decrease concerns about the future, having savings that can support the older adults in emergency and even help them to purchase pads to help them deal with episodes on UI. This is in agreement with a study done by Mohamed et al. (2010) ${ }^{(20)}$ in Egypt who found a negative relation between QoL domains and socioeconomic status. On the other hand, Kang, Phet al. (2010) ${ }^{(43)}$ found that there were no significant association between the socioeconomic status and the total QoL scores. The possible explanation for that is the availability of the medical and social insurance for the studied women in the previous study. Contrary the current studied women don't have any medical or social insurance.

As for the relation between QoL domains of the studied women and their self-esteem, the present study revealed that the lower the self esteem the worse the quality of life. Similar results were reported by Tozun et al. (2009) ${ }^{(44)}$, Bartoli et al $(2010)^{(45)}$ and Ünsal et al. (2013) ${ }^{(46)}$ who found that many aspects of a patient's life are impaired.

The present study revealed a positive relation between duration of urinary incontinence and mean score of QoL, and self esteem of the studied female elders. The longer the duration of UI the worse the QoL is and the lower self esteem of the studied elders. A statistically significant relation was found only with QoL (table 6). Therefore, gerontological nurses apart from their efforts for decreasing the number of episodes of urinary leakage should consider the detrimental effects of this problem on elders' psychological and social wellbeing in order to promote quality of life of older adults.

\section{Conclusion}

In the light of the study findings, it can be concluded that, urinary incontinence had a great impact on all domains of the quality of life of the study females. Unexpectedly, one half of the study female elders reported high self-esteem, however, the majority of them also reported that they 
do not seek any help because of shame, embarrassment and thinking that they can deal with that UI, and most importantly they believe that UI is a common condition associated with aging. Moreover, duration of UI affect the QoL, the longer the duration of UI the worst the self esteem and QoL of the studied females.

\section{Recommendations}

- Nurses have an important role in establishing good, friendly, and trustful relations with the residents in assisted living facilities in order to gain their cooperation. This in turn will help them to discuss freely any problem facing them particularly UI, and help in early detection and institute appropriate interventions.
- Raising awareness of the older adult females about UI and importance of seeking advice early in order to help them to cope with the condition, increase their self esteem, and improve their QoL.

- Nurses in assisted living facilities should include in their plan of care an exercise program to strengthen the pelvic floor muscle pyramid of older female residents

- Nurses in the different health care settings should be encouraged to assess the QoL for older adult females in order to identify any deviation from normal and intervene immediately. 
Table (1): Distribution of the studied elderly females according to their history of urinary incontinence

\begin{tabular}{|c|c|c|}
\hline Items & Frequency & $\%$ \\
\hline \multicolumn{3}{|l|}{ Duration of UI } \\
\hline - $\quad$ less than 6 months & 5 & 5.0 \\
\hline-6 months - & 11 & 11.0 \\
\hline - 3 years and more & 84 & 84.0 \\
\hline \multicolumn{3}{|l|}{ Occurrence of episode of UI } \\
\hline - $\quad$ During the day only & 38 & 38.0 \\
\hline - Day and Night & 62 & 62.0 \\
\hline \multicolumn{3}{|l|}{ Go to bathroom at night } \\
\hline - No & 16 & 16.0 \\
\hline - Once & 12 & 12.0 \\
\hline - Twice & 11 & 11.0 \\
\hline - $\quad$ More than two times & 61 & 61.0 \\
\hline \multicolumn{3}{|l|}{ State when UI occurs } \\
\hline - Awake & 54 & 54.0 \\
\hline - $\quad$ Sleepy but felt it & 5 & 5.0 \\
\hline - $\quad$ Both of them & 41 & 41.0 \\
\hline \multicolumn{3}{|l|}{ Amount of lost urine } \\
\hline - $\quad$ Wet the underwear and clothes & 47 & 47.0 \\
\hline - $\quad$ Wet the underwear only & 45 & 45.0 \\
\hline - Wet the clothes and the bed & 8 & 8.0 \\
\hline \multicolumn{3}{|l|}{ Help - seeking behaviors: } \\
\hline - Don't tell anyone & 55 & 55.0 \\
\hline - Consult nurse or physician immediately & 26 & 26.0 \\
\hline - $\quad$ Consult nearest person & 19 & 19.0 \\
\hline The reasons for not seeking help: & $\mathbf{n}(\mathbf{5 5})$ & \\
\hline - Embarrassment & 39 & 70.9 \\
\hline - Can deal with the problem & 25 & 45.4 \\
\hline - Consider it as an age related changes & 23 & 41.8 \\
\hline
\end{tabular}

\# More than one answer was given 
$*$ (15Low self-esteem (Less than

$\square$ 15-Within normal range of self-esteem (

$(25$

$\square$ (25High self-esteem (More than

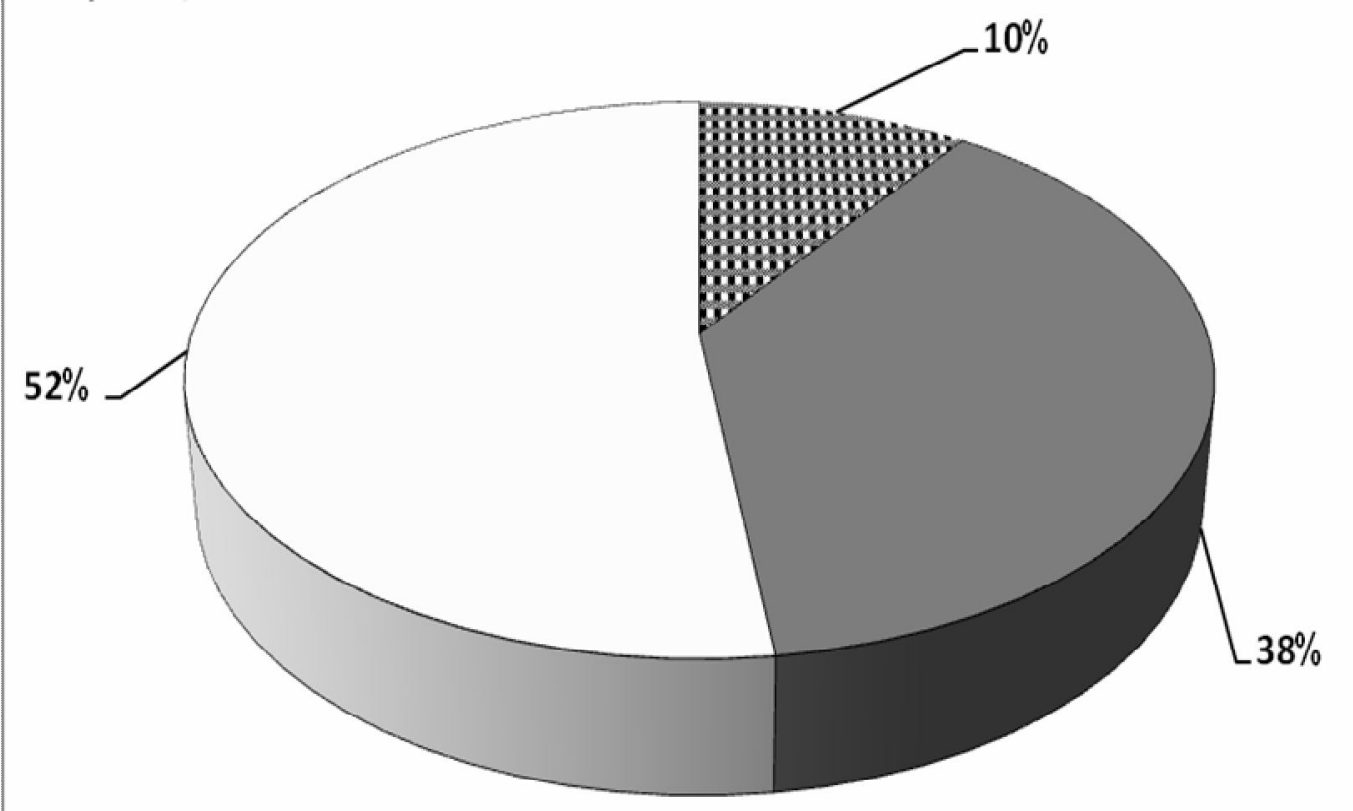

Figure (1)Distribution of the studied elderly females according to their Self-Esteem (The Rosenberg SelfEsteem Scale) 
Table (2): Relation between self-esteem of the studied elderly females and their sociodemographic characteristics

\begin{tabular}{|c|c|c|c|c|c|c|c|c|c|c|}
\hline \multirow{3}{*}{$\begin{array}{l}\text { Socio- } \\
\text { demographic } \\
\text { characteristics }\end{array}$} & \multicolumn{6}{|c|}{ Self-Esteem } & \multirow{2}{*}{\multicolumn{2}{|c|}{ Total }} & \multicolumn{2}{|c|}{$\begin{array}{c}\text { Test of } \\
\text { significance }\end{array}$} \\
\hline & \multicolumn{2}{|c|}{$\begin{array}{l}\text { Low self- } \\
\text { esteem (Less } \\
\text { than 15) }\end{array}$} & \multicolumn{2}{|c|}{$\begin{array}{c}\text { Within } \\
\text { normal } \\
\text { range of self- } \\
\text { esteem (15- } \\
25) \\
\end{array}$} & \multicolumn{2}{|c|}{$\begin{array}{l}\text { High self- } \\
\text { esteem } \\
\text { (More than } \\
\text { 25) }\end{array}$} & & & \multirow[t]{2}{*}{$\begin{array}{c}\text { Fisher } \\
\text { exact } \\
\text { test }\end{array}$} & \multirow[t]{2}{*}{$P$ value } \\
\hline & $\mathrm{N}=10$ & $\%$ & $\mathrm{~N}=38$ & $\%$ & $\begin{array}{l}\mathrm{N}= \\
52\end{array}$ & $\%$ & $\begin{array}{l}\mathrm{N}= \\
100\end{array}$ & $\%$ & & \\
\hline \multicolumn{11}{|l|}{ Age (year) } \\
\hline $60-$ & 6 & 60.0 & 18 & 47.4 & 24 & 46.2 & 48 & 48.0 & \multirow{2}{*}{0.682} & \multirow{2}{*}{0.321} \\
\hline $75+$ & 4 & 40.0 & 20 & 52.6 & 28 & 53.8 & 52 & 52.0 & & \\
\hline \multicolumn{11}{|l|}{ Marital status } \\
\hline Widow & 4 & 40.0 & 19 & 50.0 & 32 & 61.5 & 55 & 55.0 & \multirow{3}{*}{5.589} & \multirow{3}{*}{$0.030 *$} \\
\hline Divorced & 4 & 40.0 & 14 & 36.8 & 9 & 17.3 & 27 & 27.0 & & \\
\hline Single & 2 & 20.0 & 5 & 13.2 & 11 & 21.2 & 18 & 18.0 & & \\
\hline \multicolumn{11}{|l|}{$\begin{array}{l}\text { Level of } \\
\text { education }\end{array}$} \\
\hline Illiterate & 1 & 10.0 & 2 & 5.3 & 4 & 7.7 & 7 & 7.0 & \multirow{5}{*}{10.349} & \multirow{5}{*}{0.348} \\
\hline Read and write & 5 & 50.0 & 18 & 47.4 & 20 & 38.5 & 43 & 43.0 & & \\
\hline Basic education & 3 & 30.0 & 11 & 28.9 & 25 & 48.1 & 39 & 39.0 & & \\
\hline Secondary level & 0 & 0.0 & 2 & 5.3 & 3 & 5.8 & 5 & 5.0 & & \\
\hline $\begin{array}{l}\text { University and } \\
\text { higher }\end{array}$ & 1 & 10.0 & 5 & 13.2 & 0 & 0.0 & 6 & 6.0 & & \\
\hline \multicolumn{11}{|l|}{ Occupation } \\
\hline Housewife & 8 & 80.0 & 29 & 76.3 & 41 & 78.8 & 78 & 78.0 & \multirow{2}{*}{0.108} & \multirow{2}{*}{0.541} \\
\hline Employee & 2 & 20.0 & 9 & 23.7 & 11 & 21.2 & 22 & 22.0 & & \\
\hline \multicolumn{11}{|l|}{ Income } \\
\hline Enough & 9 & 90.0 & 28 & 73.7 & 42 & 80.8 & 79 & 79.0 & \multirow{2}{*}{1.575} & \multirow{2}{*}{0.567} \\
\hline Not enough & 1 & 10.0 & 10 & 26.3 & 10 & 19.2 & 21 & 21.0 & & \\
\hline
\end{tabular}

NB: Personal Relationships treated as missing value (omitted)

* Significant value at $\mathrm{P}<0.05$ 


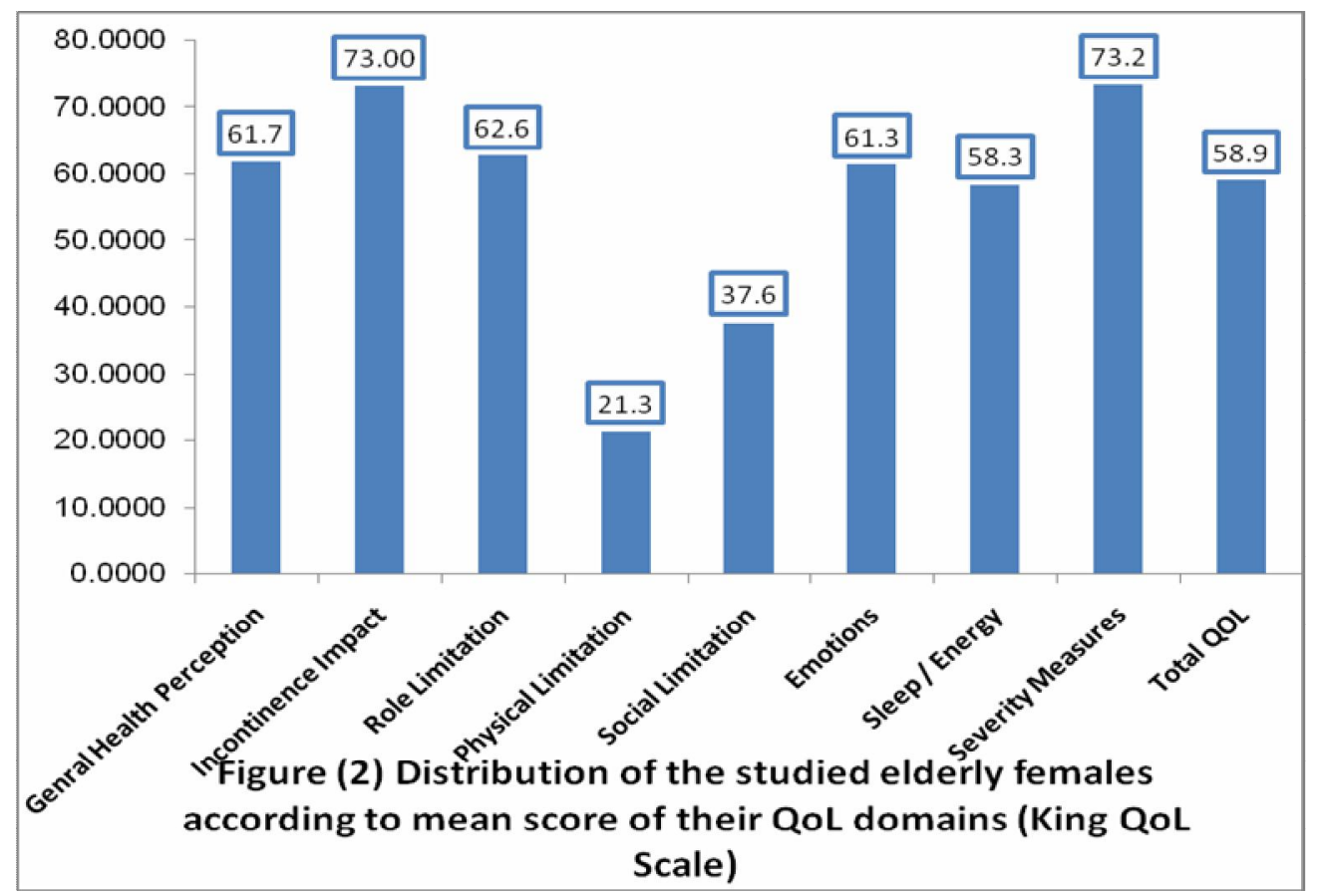

Table (3): Relation between socio-demographic characteristics and total mean score of the quality of life of studied elderly females

\begin{tabular}{|c|c|c|c|}
\hline \multirow{2}{*}{ Socio-demographic characteristics } & \multirow{2}{*}{$\frac{\text { QoL }}{\text { Mean } \pm \text { SD }}$} & \multicolumn{2}{|c|}{ Test of significance } \\
\hline & & $\mathbf{F}$ & $P$ value \\
\hline \multicolumn{4}{|l|}{ Age (Years) } \\
\hline $60-$ & $41.39 \pm 13.65$ & \multirow{2}{*}{0.854} & \multirow{2}{*}{$0.009 *$} \\
\hline $75+$ & $38.92 \pm 13.09$ & & \\
\hline \multicolumn{4}{|l|}{ Marital status } \\
\hline Widow & $39.40 \pm 13.83$ & \multirow{3}{*}{0.703} & \multirow{3}{*}{$0.014 *$} \\
\hline Divorced & $39.29 \pm 13.23$ & & \\
\hline Single & $43.50 \pm 12.200$ & & \\
\hline \multicolumn{4}{|l|}{ Level of education } \\
\hline Illiterate & $43.14 \pm 9.26$ & \multirow{5}{*}{1.689} & \multirow{5}{*}{0.066} \\
\hline Read and write & $43.04 \pm 13.21$ & & \\
\hline Basic education & $37.64 \pm 13.19$ & & \\
\hline Secondary level & $40.80 \pm 17.62$ & & \\
\hline University and over & $31.00 \pm 12.58$ & & \\
\hline \multicolumn{4}{|l|}{ Occupation before retirement } \\
\hline Housewife & $41.14 \pm 13.17$ & \multirow{2}{*}{2.136} & \multirow{2}{*}{$0.021 *$} \\
\hline Employee & $36.45 \pm 13.66$ & & \\
\hline \multicolumn{4}{|l|}{ Income } \\
\hline Not enough & $64.07 \pm 19.99$ & \multirow{2}{*}{1.799} & \multirow{2}{*}{$0.018 *$} \\
\hline Enough & $57.63 \pm 19.45$ & & \\
\hline
\end{tabular}

*Significant value at $\mathrm{P}<0.05$ 
Elderly Urinary Incontinence, Self Esteem and Quality of Life

Table (4): Relation between socio-demographic characteristics and Q0L domains of the studied elderly females

\begin{tabular}{|c|c|c|c|c|c|c|c|c|c|}
\hline \multirow{2}{*}{\multicolumn{2}{|c|}{$\begin{array}{l}\text { Socio-demographic } \\
\text { characteristics }\end{array}$}} & \multicolumn{8}{|c|}{ QoL Domains } \\
\hline & & $\begin{array}{c}\text { General } \\
\text { Health } \\
\text { Perception }\end{array}$ & $\begin{array}{l}\text { Incontinence } \\
\text { Impact }\end{array}$ & $\begin{array}{c}\text { Role } \\
\text { Limitation }\end{array}$ & $\begin{array}{l}\text { Physical } \\
\text { Limitation }\end{array}$ & $\begin{array}{c}\text { Social } \\
\text { Limitation }\end{array}$ & Emotions & Sleep / Energy & $\begin{array}{l}\text { Severity } \\
\text { Measures }\end{array}$ \\
\hline \multicolumn{10}{|l|}{ Age (Years) } \\
\hline $60-$ & $\begin{array}{l}\text { Meant } \\
\text { SD }\end{array}$ & $64.06 \pm 31.75$ & $74.30 \pm 30.93$ & $67.01 \pm 34.63$ & $23.61 \pm 17.13$ & $40.62 \pm 32.59$ & $64.58 \pm 43.04$ & $61.45 \pm 31.53$ & $75.17 \pm 30.38$ \\
\hline $75+$ & Mean $\pm S D$ & $59.61 \pm 30.97$ & $71.79 \pm 31.23$ & $58.65 \pm 33.57$ & $19.23 \pm 17.89$ & $34.93 \pm 30.11$ & $58.33 \pm 41.68$ & $55.44 \pm 30.73$ & $71.47 \pm 29.39$ \\
\hline \multicolumn{2}{|l|}{$\mathrm{F}$ (P value) } & $.502(.005)^{*}$ & $.163(.002)^{*}$ & $1.501(.015)^{*}$ & 1.558.(016)* & $.823 .(008)^{*}$ & $.544 .(006)^{*}$ & $.931 .(009)^{*}$ & $.383 .(004)^{*}$ \\
\hline \multicolumn{10}{|l|}{ Marital status } \\
\hline Widow & Mean $\pm S D$ & $60.45 \pm 32.16$ & $70.90 \pm 31.46$ & $61.51 \pm 36.27$ & $20.90 \pm 19.56$ & $36.66 \pm 31.97$ & $58.18 \pm 42.92$ & $57.57 \pm 31.88$ & $71.36 \pm 30.46$ \\
\hline Divorced & Mean $\pm S D$ & $60.18 \pm 31.20$ & $70.37 \pm 31.12$ & $60.49 \pm 31.74$ & $19.13 \pm 15.12$ & $34.56 \pm 30.98$ & $59.67 \pm 43.26$ & $56.79 \pm 30.40$ & $72.22 \pm 30.22$ \\
\hline Single & Mean $\pm S D$ & $68.05 \pm 29.46$ & $83.33 \pm 28.58$ & $69.44 \pm 31.95$ & $25.92 \pm 14.25$ & $45.37 \pm 30.14$ & $73.45 \pm 38.51$ & $62.96 \pm 31.07$ & $80.55 \pm 27.41$ \\
\hline \multicolumn{2}{|l|}{$\mathrm{F}$ (P value $)$} & $.442 .(009)^{*}$ & $1.231(0.025)^{*}$ & $.435(0.009)^{*}$ & $.838(0.017)^{*}$ & $.701(0.014)^{*}$ & $.914(0.018)^{*}$ & $.245(0.005)^{*}$ & $.663(0.013)^{*}$ \\
\hline \multicolumn{10}{|c|}{ Level of education } \\
\hline Illiterate & MeantSD & $64.28 \pm 24.39$ & $85.71 \pm 26.22$ & $71.42 \pm 28.40$ & $21.42 \pm 12.59$ & $47.61 \pm 26.22$ & $69.84 \pm 31.23$ & $54.76 \pm 24.93$ & $84.52 \pm 16.26$ \\
\hline Read and write & Mean $\pm S D$ & $67.44 \pm 32.52$ & $78.29 \pm 30.76$ & $69.37 \pm 33.90$ & $25.19 \pm 17.20$ & $43.41 \pm 31.94$ & $68.99 \pm 42.10$ & $67.44 \pm 31.27$ & $79.26 \pm 28.48$ \\
\hline Basic education & Mean $\pm S D$ & $57.69 \pm 30.43$ & $68.37 \pm 30.53$ & $55.98 \pm 32.99$ & $18.80 \pm 18.00$ & $32.05 \pm 29.71$ & $55.84 \pm 42.23$ & $51.28 \pm 30.44$ & $67.73 \pm 30.41$ \\
\hline $\begin{array}{l}\text { Secondary } \\
\text { level } \\
\end{array}$ & Mean $\pm S D$ & $65.00 \pm 37.91$ & $73.33 \pm 36.51$ & $66.66 \pm 47.14$ & $20.00 \pm 21.73$ & $43.33 \pm 40.13$ & $62.22 \pm 51.87$ & $63.33 \pm 38.00$ & $71.66 \pm 38.90$ \\
\hline $\begin{array}{l}\text { University and } \\
\text { over }\end{array}$ & Mean $\pm S D$ & $41.66 \pm 25.81$ & $50.00 \pm 27.88$ & $44.44 \pm 34.42$ & $11.11 \pm 17.21$ & $16.66 \pm 27.88$ & $31.48 \pm 40.62$ & $38.88 \pm 20.18$ & $54.16 \pm 31.95$ \\
\hline \multicolumn{2}{|l|}{$\mathrm{F}$ (P value) } & $1.172(.047)^{*}$ & $1.702(.067)$ & $1.366(.054)$ & $1.247(.050)$ & $1.607(.063)$ & $1.358(.054)$ & $2.160(.083)$ & $1.688(.066)$ \\
\hline \multicolumn{10}{|l|}{ Occupation } \\
\hline Housewife & Mean $\pm S D$ & $64.10 \pm 31.36$ & $75.21 \pm 30.59$ & $64.52 \pm 33.69$ & $22.86 \pm 17.63$ & $39.52 \pm 31.10$ & $64.67 \pm 41.71$ & $60.89 \pm 31.30$ & $75.42 \pm 29.11$ \\
\hline Employee & Mean $\pm S D$ & $53.40 \pm 30.17$ & $65.15 \pm 31.66$ & $56.06 \pm 35.83$ & $15.90 \pm 16.64$ & $31.06 \pm 31.82$ & $49.49 \pm 42.92$ & $49.24 \pm 29.31$ & $65.53 \pm 31.52$ \\
\hline \multicolumn{2}{|l|}{$\mathrm{F}$ (P value) } & $2.027(.020) *$ & $1.828(.018)^{*}$ & $1.054(.011)^{*}$ & $2.732(.027)^{*}$ & $1.259(.013)^{*}$ & $2.243(.022)^{*}$ & $2.443(.024)^{*}$ & $1.912(.019)^{*}$ \\
\hline \multicolumn{10}{|l|}{ Income } \\
\hline Not enough & Mean $\pm S D$ & $70.23 \pm 33.18$ & $79.36 \pm 30.68$ & $69.04 \pm 35.07$ & $23.80 \pm 19.41$ & $44.44 \pm 31.76$ & $71.42 \pm 42.10$ & $70.63 \pm 31.58$ & $80.55 \pm 28.78$ \\
\hline Enough & MeantSD & $59.49 \pm 30.56$ & $71.30 \pm 31.00$ & $60.97 \pm 33.95$ & $20.67 \pm 17.13$ & $35.86 \pm 31.13$ & $58.64 \pm 42.13$ & $55.06 \pm 30.35$ & $71.30 \pm 29.91$ \\
\hline \multicolumn{2}{|l|}{$\mathrm{F}$ (P value) } & $1.978(.020)^{*}$ & $1.125(.011)^{*}$ & $.926(.009)^{*}$ & $.525(.005)^{*}$ & $1.249(.013)^{*}$ & $1.526(.015)^{*}$ & $4.294(.042)^{*}$ & $1.609(.016)^{*}$ \\
\hline
\end{tabular}

NB: Personal Relationships treated as missing value (omitted)

* Significant value at $\mathrm{P}<0.05$

ASNJ Vol.19 No. 1, 2017 
Table (5): Relation between mean score of QoL domains of the studied female elders and their self-esteem

\begin{tabular}{||l|c|c|c|c|c||}
\hline \multirow{4}{*}{ QOL Domains } & \multicolumn{2}{|c||}{ Mean Self-Esteem } & \multicolumn{2}{c||}{ Test of significance } \\
\cline { 2 - 6 } & $\begin{array}{c}\text { Low self- } \\
\text { esteem (Less } \\
\text { than 15) }\end{array}$ & $\begin{array}{c}\text { Within } \\
\text { normal } \\
\text { range of self- } \\
\text { esteem (15- } \\
\text { 25) }\end{array}$ & $\begin{array}{c}\text { High self- } \\
\text { esteem } \\
\text { More than } \\
\text { 25) }\end{array}$ & F & \multirow{2}{*}{ P value } \\
\cline { 2 - 6 } & Mean \pm SD & Mean \pm SD & Mean \pm SD & & \\
\hline $\begin{array}{l}\text { General Health } \\
\text { Perception }\end{array}$ & $65.00 \pm 31.62$ & $62.50 \pm 32.75$ & $60.57 \pm 30.65$ & 0.100 & $0.002^{*}$ \\
\hline Incontinence Impact & $80.00 \pm 32.20$ & $72.80 \pm 31.81$ & $71.79 \pm 30.52$ & 0.292 & $0.006^{*}$ \\
\hline Role limitations & $71.66 \pm 31.47$ & $63.59 \pm 38.91$ & $60.25 \pm 31.16$ & 0.485 & $0.010^{*}$ \\
\hline Physical Limitations & $33.33 \pm 15.71$ & $18.85 \pm 19.82$ & $20.83 \pm 15.43$ & 2.827 & 0.055 \\
\hline Social Limitations & $43.33 \pm 32.58$ & $39.91 \pm 33.67$ & $34.93 \pm 29.56$ & 0.454 & $0.009^{*}$ \\
\hline Emotions & $66.66 \pm 44.13$ & $61.40 \pm 43.51$ & $60.25 \pm 41.71$ & 0.095 & $0.002^{*}$ \\
\hline Sleep/Energy & $61.66 \pm 32.44$ & $60.52 \pm 32.05$ & $56.08 \pm 30.61$ & 0.283 & $0.006^{*}$ \\
\hline Severity Measures & $78.33 \pm 31.47$ & $73.02 \pm 30.78$ & $72.43 \pm 29.22$ & 0.163 & $0.003^{*}$ \\
\hline Total Quality of Life & $63.23 \pm 19.75$ & $59.21 \pm 21.18$ & $58.00 \pm 18.71$ & 0.297 & $0.006^{*}$ \\
\hline
\end{tabular}

NB: Personal Relationships treated as missing value (omitted)

* Significant value at $\mathrm{P}<0.05$

Table (6): Relation between mean total score of the QoL and self-esteem of the studied elderly females and their duration of urinary incontinence

\begin{tabular}{|c|c|c|c|c|c|c|}
\hline \multirow{3}{*}{ Duration of UI } & \multirow{3}{*}{$\begin{array}{c}\text { QOL } \\
\text { Mean } \pm \text { SD }\end{array}$} & \multicolumn{2}{|c|}{$\begin{array}{c}\text { Test of } \\
\text { significance }\end{array}$} & \multirow{3}{*}{$\begin{array}{c}\text { Mean Self- } \\
\text { Esteem }\end{array}$} & \multirow{2}{*}{\multicolumn{2}{|c|}{$\begin{array}{c}\text { Test of } \\
\text { significance }\end{array}$}} \\
\hline & & \multirow{2}{*}{$\mathbf{F}$} & \multirow{2}{*}{$\begin{array}{c}\mathbf{P} \\
\text { value }\end{array}$} & & & \\
\hline & & & & & $\mathbf{F}$ & $P$ value \\
\hline - Less than 6 months & $49.11 \pm 69.33$ & \multirow{3}{*}{1.154} & \multirow{3}{*}{$.023 *$} & $15.40 \pm 25.21$ & \multirow{3}{*}{2.538} & \multirow{3}{*}{.050} \\
\hline-6 months - & $54.01 \pm 22.48$ & & & $88.18 \pm 8.98$ & & \\
\hline-3 years and more & $60.22 \pm 19.42$ & & & $77.34 \pm 17.79$ & & \\
\hline
\end{tabular}

* Significant value at $\mathrm{P}<0.05$ 


\section{References}

1. Minassian V, Drutz H, Al-Badr A. Urinary incontinence as a worldwide problem. International Journal of Gynecology and Obstetrics. 2003; 82(3): 27-38.

2. Lee J. The impact of urinary incontinence levels on the social lives of older Chinese in Hong Kong. Hallym. International Journal of Aging 2005; 7(1): 63-80.

3. Gotoh M. Quality of life assessment for patients with urinary incontinence. Nagoya Journal of Medical Science 2007; 69(3-4): 123-31.

4. Burgio K, Goode $\mathrm{P}$, Richter $\mathrm{H}$. Combined behavioral and individualized drug therapy versus individualized drug therapy alone for urge incontinence in women. The Journal of Urology 2010; 18(4): 598-603.

5. Australian Institute of Health and Welfare. Australian incontinence data analysis and development. Canberra: Australian Institute of Health and Welfare; 2006. AIHW cat. no. DIS44. Available at: http://www.aihw.gov.au/WorkArea/Dow nloadAsset. aspx?id=6442455813.

Retrieved on: 3-4-2017.

6. Perry S, McGrother C, Turner K. An investigation of the relationship between anxiety and depression and urge incontinence in women: Development of a psychological model. British Journal of health Psychology 2006; 11(3): 463-82.

7. E 1-Azab A. Mohamed E, Sabra H .The prevalence and risk factors of urinary incontinence and its influence on the quality of life among Egyptian women. Neurourology and Urodynamic Journal 2007; 26(6): 783-8.

8. Goode P, Burgio K, Redden D, Makland A, Richter HE, Sawyer P. Population based study of incidence and predictors of urinary incontinence in black and white older adults. The Journal of Urology 2008; 17(9): 1449-53.

9. Jonsson F, Siddiqui N, Kawasaki A. Long-term outcomes after stress urinary incontinence surgery. Journal of Obstetrics and Gynecology .2012; 12(1):83-90.

10. Garcia J, Crocker J, Wyman J, Krissovich M. Breaking the Cycle of Stigmatization: Managing the Stigma of Incontinence in Social Interactions. Journal of Wound Ostomy and Continence Nursing 2005; 32(1): 38-52.

11. Huang J, Brown S, Thom D, Fink H, Yaffe K. Urinary incontinence in older community dwelling women: the role of cognitive and physical function decline. Journal of Obstetrics and Gynecology 2007; 10(9): 909-16.

12. Du Beau. The effect of urinary incontinence on quality of life in older nursing home residents. Journal of the American Geriatrics Society 2006 54(9): 1325-33.

13. Virkud A. Management of stress urinary incontinence. Clinical Obstetrics and Gynecology Journal 2011; 25(2): 20516.

14. Nilsson M, Lalos A, Lalos O. The impact of female urinary incontinence and urgency on quality of life and partner relationship. Neurourology and Urodynamic Journal 2009; 28(8): 97681.

15. Shaw C. A review of the psychosocial predictors of help seeking behavior and impaction quality of life in people with urinary incontinence. Journal of Clinical Nursing 2001; 10(1): 15-24.

16. Barber M, Visco A, Wyman J, Fantl J, Bump RC; Continence Program for Women Research Group. Sexual 
function in women with urinary incontinence and pelvic organ prolapse. The American Journal of Obstetrics and Gynecology 2002; 99(2): 281-9.

17. Yip S, Cardozo L. Psychological morbidity and female urinary incontinence. Best Practice and Research Clinical Obstetrics and Gynecology Journal 2007; 21(2): 321-9.

18. Heidrich S, Wells T. Effects of urinary incontinence: psychological well-being and distress in older communitydwelling women. Journal of Gerontological Nursing 2004; 30(1): 4754.

19. Rosenberg, M. Society and the adolescent self-image. Princeton, NJ: Princeton University Press 1965 Available at: http://www.zentactics.com/contactform.html. Retrieved on: 04-7-2017.

20. Ebrahim N, Elsebie N, Fouad R. Assessment of student's self-esteem at the Faculty of Nursing, Alexandria University. The 9th international Scientific Nursing conference, the 2nd Scientific Association of Arab Nursing Faculties conference "Accreditation and Nursing" 2007.

21. Kelleher C, Cardozo L, Khullar V, Salvatore S. A new questionnaire to assess the quality of life of urinary incontinent women. British Journal of Obstetrics and Gyneco logy 1997; 104(1): 1374-9.

22. Mohammed S, Karmallawy E, Mohamed R. Assessing Quality Of Life Of Women With Urinary Incontinence. Egyptian Journal of Nursing 2015; 10(1): 1-17.

23. Abd El Geleel A. Effect of behavioral training program on the continence outcome for incontinent institutionalized elderly women. Unpublished Doctorate
Dissertation, Alexandria University, Faculty of Nursing, Egypt, 2012.

24. Horrocks S, Somerset M, Stoddart H, Peters J. What prevents older people from seeking treatment for urinary incontinence? A qualitative exploration of barriers to the use of community continence services. Journal of Family Practice 2004; 21(6): 689-96.

25. Newman D. Report of a mail survey of women with bladder control disorders. Urologic Nursing Journal 2004; 24(6): 499-507.

26. Kirss F, Lang K, Toompere K, Veerus P. Prevalence and risk factors of urinary incontinence among Estonian postmenopausal women. Springer Plus 2013; 2(3): 524.

27. Manonai J, Wattanayingcharoenchai R, Sarit-apirak S, Vannatim N, Chittacharoen A. Prevalence and risk factors of anorectal dysfunction in women with urinary incontinence. Obstetric and Gynecology Journal 2010; 28(1): 105.

28. Thomas A, Morse J .Managing urinary incontinence with self-care practices. Journal of Gerontological Nursing 1991; 63(5): 17-9.

29. Chedraui P, Pérez-López R, Mendoza M, Leimberg M, Martinez M , Vallarino $\mathrm{V}$, Hidalgo L. Assessment of self-esteem in mid-aged women. Journal of Maturitas 2010; 66(1):77-82.

30. Bergland A, Thoresen K. The relationship between coping, self-esteem and health on outdoor walking ability among older adults in Norway and Nina Wallre Lolandsal. Journal of Ageing \& Society 2010; 30(1): 949-63.

31. Kim S, Bae J, Cho M, Lee K, Lee H, Jun T. Effect of preoperative flow rate on postoperative retention and voiding difficulty after transobturator tape 
operation. Korean Journal of Urology 2014; 55(3):190-5.

32. Young J, Kyungeh A, Connor L, Wexler S. Life Satisfaction, Self-Esteem, and Perceived Health Status Among Elder Korean Women: Focus on Living Arrangements. Journal of Transcultural Nursing 2008; 19(2): 151-60.

33. Franak J, Alireza K, Malek M. SelfEsteem among the Elderly Visiting the Healthcare Centers in Kermanshah-Iran. Global Journal of Health Science 2012; 7(5): 352-358.

34. Bertera EM. Depression in older Americans with urinary incontinence (UI): the relationship with activities of daily living (ADL) and avoidance behaviors. Journal of Gerontological Social Work 2002; 39(4): 39-53.

35. Hajjar RR. Psychosocial impact of urinary incontinence in the elderly population. Clinics in Geriatric Medicine Journal 2004; 20(3): 553-64.

36. Sinclair A, Ramsay I. The psychosocial impact of urinary incontinence in women. Obstetrician and Gynaecologist Journal 2011; 13(1):143-148.

37. Kocak I, Okyay P, Dundar M, Erol H, Beser E. Female Urinary Incontinence in the West of Turkey: Prevalence, Risk Factors and Impact on Quality of Life. European Urology Journal 2005; 48: 634-41.

38. Teunisse D, Bosch W, Weel C, LagroJanssen T. "It can always happen": The impact of urinary incontinence on elderly men and women. Scandinavian Journal of Primary Health Care 2006; 24(2): 166-73.

39. Mladenović S, Segedi D, Parezanović I. Quality of life in women with urinary incontinence. Med Glas Ljek komore
Zenicko-doboj Kantona Journal 2011; 8(1): 237-42.

40. Kalda R, Rätsep A, Lember M. Predictors of quality of life of patients with type 2 diabetes. Journal of Patient Preferences and Adherence 2008; 2(1): 21-6.

41. El husseini S. Effect of self care interventions on the quality of life of older adults with heart failure. Unpublished Doctorate Dissertation, Alexandria University, Faculty of Nursing, Egypt, 2013.

42. Ibrahim N. Effect of oral health care interventions on oral health related quality of life of institutionalized older adults. Unpublished Doctorate Thesis, Mansoura University, Faculty of Nursing, Egypt, 2014.

43. Kang Y, Phillips L, Sun K. Incontinence Quality of Life among Korean-American Women. Urologic Nursing Journal 2010; 2(30):133.

44. Tozun, M, Ayranci, U, Unsal, A. Prevalence of urinary incontinence among women and its impact on quality of life in a semirural area of western Turkey. Gynecologic and Obstetric Investigation Journal 2009; 67(4): 24149.

45. Bartoli S, Aguzzi G, and Tarricone R. Impact on Quality of Life of Urinary Incontinence and Overactive Bladder: A Systematic Literature Review. Urology Journal 2010; 75(3): 491.

46. Ünsal A, Tözün M, Arslantaş D. Urinary Incontinence, Related Factors and Depression among 20 Aged and Over Women in Beylikova District Centre in Eskişehir, Scope Meical Journal 2013; 12(3): 232. 